\title{
First-pass Gastric Mucosal Metabolism of Ethanol Is Negligible in the Rat
}

\author{
Theresa Smith,* Eugene G. DeMaster," Julie K. Fume," John Springfield, * and Michael D. Levitt** \\ ${ }^{*}$ Research Service, Veterans Affairs Medical Center, Minneapolis, Minnesota 55417; and ${ }^{\ddagger}$ Department of Medicine, \\ University of Minnesota Medical School, Minneapolis, Minnesota 55414
}

\begin{abstract}
Ethanol metabolism by gastric alcohol dehydrogenase (ADH) is thought to be an important determinant of peripheral ethanol time-concentration curves (AUCs) in rats and humans. We quantitated this metabolism in rats by measuring the gastric absorption of oral ethanol $(0.25 \mathrm{~g} / \mathrm{kg})$ and the gastric venousarterial (V-A) difference of ethanol versus ethanol metabolites (acetate, acetaldehyde, and bicarbonate). Over $1 \mathrm{~h}, \sim 20 \%$ of the ethanol was absorbed from the stomach and $70 \%$ was emptied into the duodenum. The gastric $\mathrm{V}$-A difference of ethanol metabolites was $<4 \%$ of that of ethanol. Thus, gastric metabolism accounted for $<1 \%$ ( $<4 \%$ of $20 \%$ absorbed) of the dose. This negligible metabolism was predictable from the low affinity of gastric ADH for ethanol. In contrast, gastric ADH has a high affinity for octanol, and $66 \%$ of this compound was metabolized during gastric absorption. Evidence supporting gastric metabolism of ethanol largely derives from the lower AUCs observed after oral than after intravenous administration; however, we observed increasingly higher AUCs with increasingly rapid portal vein infusions of identical ethanol doses. We conclude that gastric metabolism of ethanol is negligible in the rat, and differences in AUCs ascribed to gastric metabolism may reflect differences in ethanol absorption. (J. Clin. Invest. 1992. 89:1801-1806.) Key words: octanol • alcohol dehydrogenase • gastric absorption • alcoholism • gastric emptying
\end{abstract}

\section{Introduction}

Isozymes of alcohol dehydrogenase $(\mathrm{ADH})^{1}$ are present in the gastric mucosa of humans and rats $(1-5)$, and it has been proposed that gastric ADH metabolizes $20-80 \%$ of ingested ethanol (6-8). Decreased gastric metabolism of ingested ethanol in females compared with males has been offered as an explanation for the increased vulnerability of females to ethanol (9). Medications such as some $\mathrm{H}-2$ blockers and aspirin are said to inhibit gastric ADH activity, causing higher-than-expected blood ethanol levels $(10,11)$. Chronic ethanol exposure is thought to decrease gastric metabolism of ethanol in humans $(8,9)$, thus increasing the systemic exposure to this toxin.

Portions of this work have appeared in abstract form (1991. Gastroenterology. 100:A798).

Address correspondence to Michael D. Levitt, M.D., Veterans Affairs Medical Center (151), One Veteran's Drive, Minneapolis, MN 55417.

Received for publication 14 October 1991 and in revised form 14 January 1992.

1. Abbreviations used in this paper: $\mathrm{ADH}$, alcohol dehydrogenase; AUC, area under the curve; GC, gas chromatography; V-A, venousarterial.

The Journal of Clinical Investigation, Inc.

Volume 89, June 1992, 1801-1806
The majority of studies purporting to document gastric metabolism of ethanol have examined differences in peripheral blood ethanol time-concentration curves after oral versus intravenous administration of ethanol (6-12). These studies, initially carried out in rats and then in humans, demonstrated lower peak blood ethanol concentrations and decreased areas under the curve (AUC) with oral administration. Additional evidence cited to support the concept of gastric metabolism of ethanol is the finding of higher concentrations of ethanol metabolites in portal vein versus arterial blood after gastric instillation of ethanol in pylorus-ligated rats $(13,14)$.

The above evidence does not, however, provide a compelling argument in support of appreciable ethanol metabolism by the gastric mucosa. To metabolize $20-80 \%$ of an ingested dose of ethanol, gastric metabolism must approach $100 \%$ of the ethanol absorbed from the stomach since an appreciable fraction is emptied into the duodenum. However, a sizable fraction of a comparable quantity of ethanol escapes first-pass metabolism in the liver, although the total hepatic ADH activity is manyfold greater than that of the stomach and the $K_{\mathrm{m}}$ for ethanol of hepatic ADH is orders of magnitude lower than that of the gastric enzyme $(4,5)$. Thus, it would seem unlikely that gastric mucosal ADH could account for $20-80 \%$ of the total body metabolism of ethanol. The demonstration of first-pass metabolism via comparison of AUCs after oral and intravenous drug administration requires that clearance follow first-order kinetics (15). However, hepatic ADH is readily saturated by small doses of ethanol, with resultant zero-order removal kinetics (16). Last, the reported venous-arterial (V-A) differences in ethanol metabolites across the stomach $(13,14)$ were trivial relative to that of ethanol, a result that argues against, rather than for, appreciable ethanol metabolism by the stomach. Perhaps the best evidence for gastric metabolism of ethanol was the finding that the maintenance of similar blood ethanol levels required a more rapid constant infusion of ethanol when administered intragastrically versus intravenously (7). However, interpretation of this study is complicated by the accumulation of ethanol in the gastrointestinal tract of the animals receiving intragastric ethanol.

In this study we first quantitated the gastric mucosal metabolism of an orally administered load of ethanol in the rat by measuring the gastric absorption of ethanol and the fraction of this absorbed ethanol that was metabolized by the stomach. Finding negligible gastric metabolism of ethanol, additional studies were carried out to demonstrate that variations in the gastrointestinal absorption rate of ethanol could readily explain previously observed differences in AUCs.

\section{Methods}

All experiments were performed on male Sprague-Dawley rats (weight $290-380 \mathrm{~g}$ ) allowed free access to standard rat chow and water until the time of the experimental procedure. 
Gastric emptying and gastric absorption of ethanol. Unanesthetized rats were gavaged with $0.25 \mathrm{~g} / \mathrm{kg}$ of ethanol in a $2.5 \%$ (wt/vol) aqueous solution containing $\left[1-{ }^{14} \mathrm{C}\right]$ ethanol $(0.25 \mu \mathrm{Ci} / \mathrm{ml})$ and $\left[{ }^{3} \mathrm{H}\right]$ polyethylene glycol (PEG) $(2.5 \mu \mathrm{Ci} / \mathrm{ml}, 0.1 \mathrm{~g} / \mathrm{dl}$, New England Nuclear, Boston, MA). Animals were killed by decapitation at 15,30 , or 60 min after administration of the ethanol and the stomach immediately was isolated with clamps. All gastric contents were quantitatively collected using two washes with $20 \mathrm{ml}$ of saline. The gastric contents and washes were then centrifuged at $5,200 \mathrm{~g}$, and the precipitate was washed with $20 \mathrm{ml}$ of saline and recentrifuged for $10 \mathrm{~min}$. The ${ }^{14} \mathrm{C}$ and ${ }^{3} \mathrm{H}$ concentrations of all the supernatants were determined by liquid scintillation counting. On the basis of the ratio of $\left[{ }^{14} \mathrm{C}\right]$ ethanol to $\left[{ }^{3} \mathrm{H}\right] \mathrm{PEG}$ remaining in the stomach, the amount of ethanol emptied through the pylorus and the amount absorbed from the stomach were calculated as described by Cooke and Birchall (17). The ethanol remaining in the gastric lumen was measured by head space gas chromatography (GC) to exclude the possibility that ${ }^{14} \mathrm{C}$-labeled compounds other than ethanol had accumulated in gastric contents. There was excellent agreement between the GC and ${ }^{14} \mathrm{C}$ measurements of ethanol. To exclude the possibility of binding of $\left[{ }^{14} \mathrm{C}\right]$ ethanol or $\left[{ }^{3} \mathrm{H}\right] \mathrm{PEG}$ to gastric contents (and hence removal during centrifugation), the gastric instillate was mixed, in vitro, with gastric contents obtained from a fed rat. Analysis of the supernatant demonstrated complete recovery of both labeled compounds.

First-pass gastric metabolism of ethanol. Animals were anesthetized with acepromazine $(3 \mathrm{mg} / \mathrm{kg})$ and ketamine $(65 \mathrm{mg} / \mathrm{kg})$ via an intraperitoneal injection, the abdomen was opened, and a catheter was passed through the duodenum into the stomach. The duodenum was ligated just distal to the pylorus and the esophagus was ligated at the gastroesophageal junction. Ethanol, $0.25 \mathrm{~g} / \mathrm{kg}$, was then instilled as a $2.5 \%$ aqueous solution into the stomach of the test animals, whereas the controls received a similar quantity of water; and at 5,10 , or $15 \mathrm{~min}$ blood $(\sim 0.5 \mathrm{ml})$ was obtained from the left gastric vein using a $27-$ gauge needle. An arterial sample was simultaneously obtained by cardiac puncture. Only one pair of blood samples was obtained from each animal (five or six animals at each time period). Blood samples from control animals were obtained $15 \mathrm{~min}$ after intragastric administration of water.

To determine the gastric V-A difference of bicarbonate derived from ethanol metabolism, the animals received an intragastric infusion of $0.25 \mathrm{~g} / \mathrm{kg}$ of $\left[1-{ }^{14} \mathrm{C}\right]$ ethanol $(2.5 \mu \mathrm{Ci} / \mathrm{ml})$ as a $2.5 \%$ (wt/vol) solution in water. Gastric vein and cardiac blood samples were collected and centrifuged anaerobically for $3 \mathrm{~min}$ at $12,000 \mathrm{~g}$. The serum $(0.5 \mathrm{ml})$ was collected anaerobically and bicarbonate was precipitated by the addition, on ice, of $1 \mathrm{ml}$ of $100 \mathrm{mM}$ unlabeled sodium bicarbonate and $2 \mathrm{ml}$ of $0.3 \mathrm{~N} \mathrm{Ba}(\mathrm{OH})_{2}$. After centrifugation for $3 \mathrm{~min}$ at $12,000 \mathrm{~g}$, the precipitate was washed with $2 \mathrm{ml}$ of cold $0.3 \mathrm{~N} \mathrm{Ba}(\mathrm{OH})_{2}$ and recentrifuged. The precipitated $\mathrm{BaCO}_{3}$ was then solubilized with $1 \mathrm{ml}$ of $0.5 \mathrm{M}$ hyamine and added to $10 \mathrm{ml}$ of scintillation cocktail (Ultima Gold; Packard Instrument Co. Inc., Downers Grove, IL) and counted in a liquid scintillation counter. The supernatants from this precipitation procedure and the wash also were counted by adding $100 \mu \mathrm{l}$ to $10 \mathrm{ml}$ of Ultima Gold and $1 \mathrm{ml}$ of $0.5 \mathrm{M}$ hyamine. Preliminary experiments with this technique using known quantities of $\left[{ }^{14} \mathrm{C}\right]$ ethanol and $\left[{ }^{14} \mathrm{C}\right]$ bicarbonate dissolved in rat serum demonstrated that $>99 \%$ of the bicarbonate and $<1 \%$ of the ethanol were present in the precipitate. To determine whether ethanol or an ethanol metabolite was bound to gastric tissue, the gastric lumen was thoroughly washed, and the stomach was then homogenized in $20 \mathrm{ml}$ of saline. A $25-\mu \mathrm{l}$ aliquot of this homogenate was added to $10 \mathrm{ml}$ of Ultima Gold and radioactivity was measured by scintillation counting.

First-pass gastric metabolism of octanol. The procedure employed was similar to that described for ethanol, with the exception that the gastric instillate consisted of $2 \mathrm{ml}$ of water containing $0.64 \mathrm{mg}$ and 7.4 $\mu \mathrm{Ci}$ of $\left[1-{ }^{14} \mathrm{C}\right]$ octanol (ICN Biomedicals Inc., Costa Mesa, CA). Gastric vein and cardiac blood samples were obtained at $5 \mathrm{~min}$ after instillation of $\left[{ }^{14} \mathrm{C}\right]$ octanol in five rats. The serum concentration of $\left[{ }^{14} \mathrm{C}\right]$ octanol versus its more polar metabolites was determined as follows. $1 \mathrm{ml}$ of water was added to $0.2 \mathrm{ml}$ of plasma, and this mixture was then extracted three times with $1 \mathrm{ml}$ of ethyl acetate. With the first extraction, it was necessary to centrifuge to obtain good separation of the two phases. The combined ethyl acetate extract was extracted three times with $1 \mathrm{ml}$ of $2 \mathrm{~N} \mathrm{NaOH}$. The radioactivity in the aqueous $(\mathrm{NaOH})$ and ethyl acetate phases was then determined by liquid scintillation counting. Studies with authentic octanol and octanoic acid in rat plasma demonstrated that $<0.1 \%$ of the octanoic acid was extracted in the ethyl acetate and $<0.5 \%$ of the octanol was in the $\mathrm{NaOH}$.

First-pass small bowel metabolism of ethanol. Via a midline incision, a 20-cm loop of small intestine beginning just beyond the pylorus was isolated between ligatures. Ethanol $(0.25 \mathrm{~g} / \mathrm{kg})$ was instilled into the intestinal segment. Arterial and portal blood samples collected at 5 , 10 , and $15 \mathrm{~min}$ were analyzed for ethanol, acetate, acetaldehyde, and $\left[{ }^{14} \mathrm{C}\right]$ bicarbonate. Four to six animals were evaluated at each time period.

Portal vein infusion of ethanol. The ileocecal vein of anesthetized rats was cannulated with PE-50 tubing and the tubing was then advanced into the portal vein. Ethanol dissolved in saline was constantly infused into the portal vein at a rate sufficient to deliver a dosage of 0.25 $\mathrm{g} / \mathrm{kg}$ over $5,15,30,60$, or 90 min using a syringe infusion pump (model 22; Harvard Apparatus Co. Inc., South Natick, MA). Tail vein blood samples were collected every $10 \mathrm{~min}$ for $60 \mathrm{~min}$ and then every $30 \mathrm{~min}$ for the subsequent $120 \mathrm{~min}$. Three to four animals were studied at each infusion rate.

GC analysis of ethanol, acetaldehyde, and acetate. For the measurement of ethanol and acetate, blood samples (or gastric contents) were immediately deproteinized with 2 vol of cold $0.6 \mathrm{~N}$ perchloric acid and then centrifuged at $4^{\circ} \mathrm{C}$ for $10 \mathrm{~min}$ at $13,000 \mathrm{~g}(18)$. Acetate was esterified to methylacetate and quantified by head space $G C$, essentially as described by Giles et al. (19). A 0.25 -ml aliquot of protein-free supernatant or acetate standard was added to a glass GC septum vial containing $0.6 \mathrm{ml}$ of an aqueous, acidified methanol solution ( 5 parts concentrated sulfuric acid, 25 parts methanol, and 30 parts water by volume). The samples were heated for $30 \mathrm{~min}$ at $55^{\circ} \mathrm{C}$ in the heating block of a gas chromatograph (model Sigma 2000; Perkin-Elmer Corp., Norwalk, CT) equipped with a head space autosampler (model HS-100; PerkinElmer Corp.) and hydrogen flame ionization detectors. The chromatography conditions were as follows: column, $1 / 8$ in $\times 6 \mathrm{ft}$ stainless steel packed with Porapak QS, 80-100 mesh (Alltech Associates, Inc., Deerfield, IL); column temperature, $130^{\circ} \mathrm{C}$; carrier gas, nitrogen; carrier gas flow rate, $40 \mathrm{ml} / \mathrm{min}$. Since methanol interfered with the analysis of ethanol under the above conditions, ethanol was assayed separately. A $0.1-\mathrm{ml}$ aliquot of the protein-free supernatant was added to a GC vial containing $0.75 \mathrm{ml}$ of $0.8 \mathrm{mM} n$-propanol (internal standard). The samples were heated for $10 \mathrm{~min}$ at $55^{\circ} \mathrm{C}$ in the heating block of the autosampler and ethanol was quantified by head space GC analysis. The following chromatography conditions were used: column, $2 \mathrm{~mm}$ (i.d.) $\times 2 \mathrm{~m}$ glass packed with Tenax GC, 80-100 mesh (Alltech Associates, Inc.); column temperature, $110^{\circ} \mathrm{C}$; carrier gas, nitrogen; carrier gas flow rate, $40 \mathrm{ml} / \mathrm{min}$. In the ethanol clearance studies, tail vein blood ethanol was measured using a modification of a method described by Coldwell et al. (20). Immediately after collection, $20 \mu \mathrm{l}$ of whole blood was expelled onto an azide-treated paper disk (no. 1 filter paper [Whatman Laboratory Products Inc., Clifton, NJ] impregnated with $1 \mathrm{M}$ sodium azide) contained within a $\mathrm{GC}$ vial followed by the addition of $4.0 \mathrm{mM} n$-propanol, internal standard. The chromatographic conditions used were the same as described for ethanol above. Blood acetaldehyde was measured as previously described (21). Blood acetaldehyde and acetate values were calculated on the basis of peak areas, whereas blood ethanol values were computed using peak area ratios with $n$-propanol as the internal standard.

\section{Results}

Gastric emptying and gastric absorption of ethanol. Fig. 1 shows the percentages of the gavaged dose of ethanol absorbed from the stomach and emptied into the duodenum at 15,30 , 


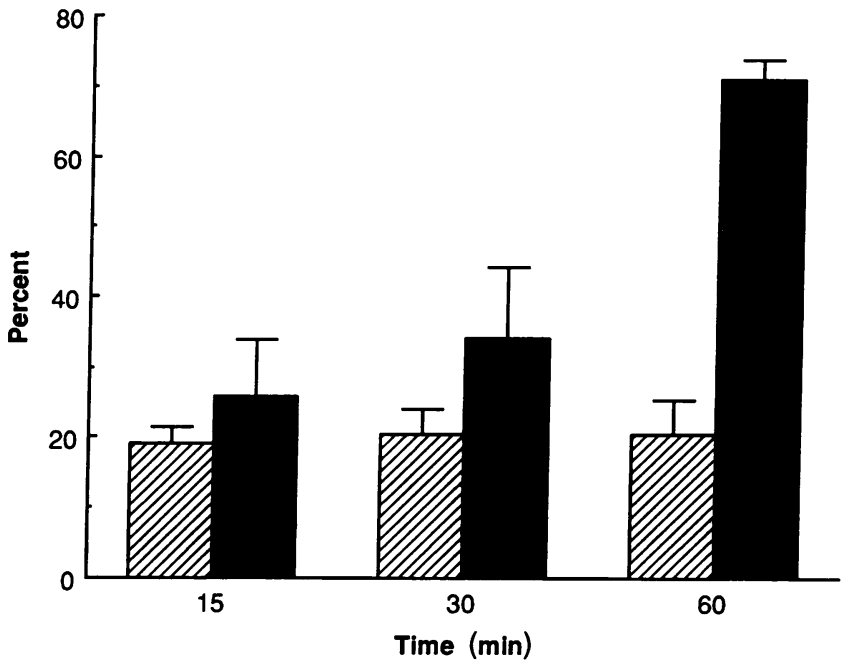

Figure 1. Percentages of ethanol absorbed from the stomach and emptied into the duodenum at 15,30 , and $60 \mathrm{~min}$ after intragastric instillation. $n$, Absorbed; $n$, emptied.

and $60 \mathrm{~min}$. The majority of ethanol absorption from the stomach occurred within the first $15 \mathrm{~min}$. By $60 \mathrm{~min}, 20 \%$ of the ethanol dose had been absorbed across the gastric mucosa and $71 \%$ had been emptied into the duodenum.

First-pass gastric metabolism of ethanol. Fig. 2 shows the $\mathrm{V}-\mathrm{A}$ differences of ethanol and acetate across the stomach. In the control animals that did not receive ethanol, there was no $\mathrm{V}$-A difference for ethanol or acetate. $5 \mathrm{~min}$ after the intragastric instillation of ethanol, there was a mean $\mathrm{V}$-A difference of ethanol of $19.0 \mathrm{mM}$ but only a $0.06 \mathrm{mM} \mathrm{V}-\mathrm{A}$ difference for acetate. At 10 and $15 \mathrm{~min}$ the $\mathrm{V}$-A differences for ethanol were 11.7 and $5.18 \mathrm{mM}$, respectively, with a V-A difference for acetate of $0.06 \mathrm{mM}$ at $10 \mathrm{~min}$ and $0.26 \mathrm{mM}$ at $15 \mathrm{~min}$. The $\mathrm{V}-\mathrm{A}$ difference for acetaldehyde at 5,10 , and $15 \mathrm{~min}$ was $<6 \mu \mathrm{M}$.

Fig. 3 shows the $\mathrm{V}-\mathrm{A}$ difference of $\left[{ }^{14} \mathrm{C}\right]$ ethanol and $\left[{ }^{14} \mathrm{C}\right]$ bicarbonate across the stomach. The V-A difference for

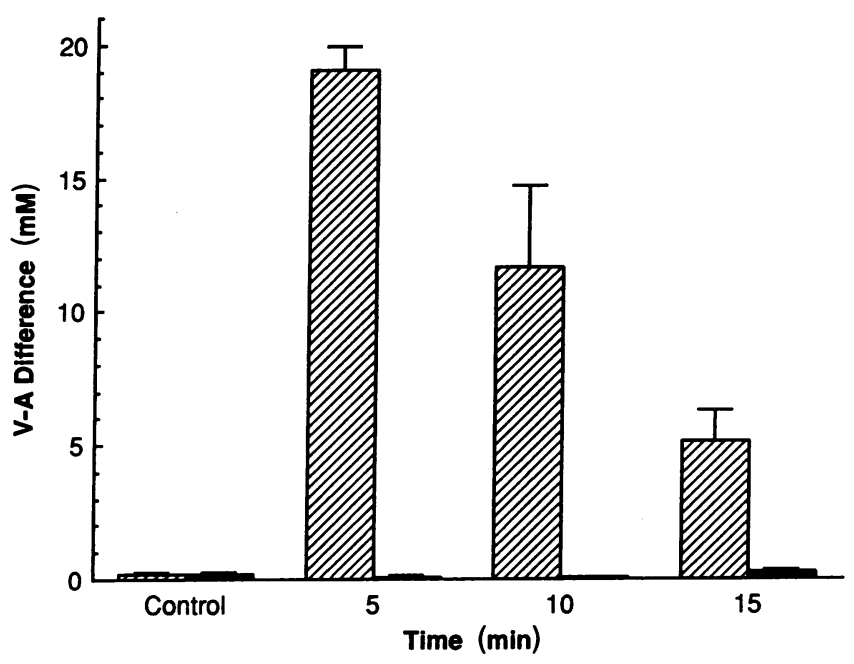

Figure 2. The V-A difference across the stomach of ethanol and acetate before and at 5,10 , and 15 min after intragastric administration of ethanol. $\square$, ETOH; $\square$, acetate.

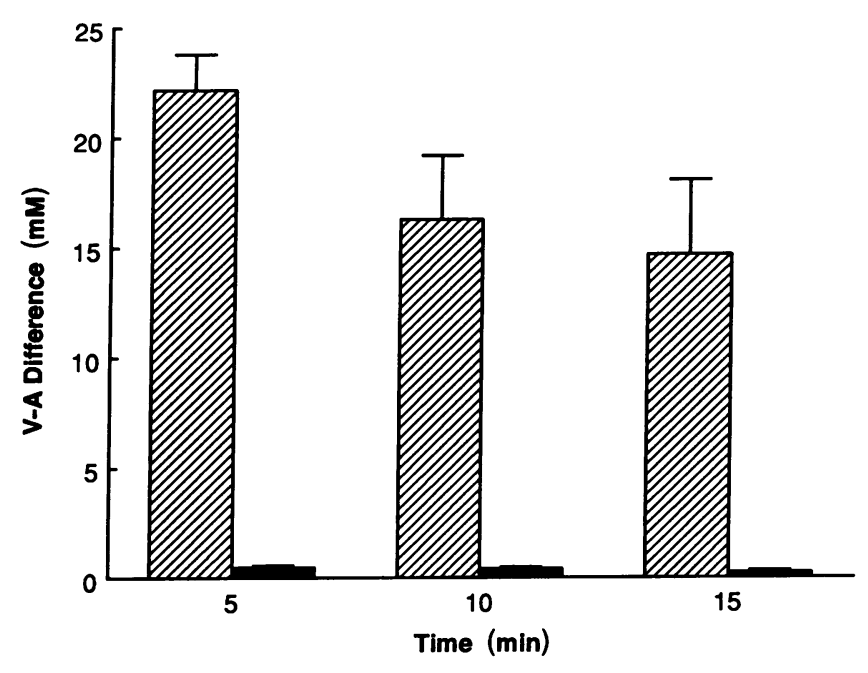

Figure 3. The V-A difference across the stomach of $\left[{ }^{14} \mathrm{C}\right]$ ethanol and $\left[{ }^{14} \mathrm{C}\right]$ bicarbonate at 5,10 , and $15 \mathrm{~min}$ after intragastric administration of $\left[1-{ }^{14} \mathrm{C}\right]$ ethanol. $a,\left[{ }^{14} \mathrm{C}\right] \mathrm{ETOH} ; \square,\left[{ }^{14} \mathrm{C}\right] \mathrm{HCO}_{3}^{-}$.

ethanol was $22.2 \mathrm{mM}$ at $5 \mathrm{~min}, 16.3 \mathrm{mM}$ at $10 \mathrm{~min}$, and 14.6 $\mathrm{mM}$ at $15 \mathrm{~min}$. The $\mathrm{V}-\mathrm{A}$ differences for $\left[{ }^{14} \mathrm{C}\right]$ bicarbonate were $0.50,0.38$, and $0.22 \mathrm{mM}$, respectively. Analysis of homogenates of the stomach wall revealed that $<1 \%$ of the instilled dose of $\left[{ }^{14} \mathrm{C}\right]$ ethanol remained in gastric tissue.

First-pass gastric metabolism of octanol. Measurements obtained at $5 \mathrm{~min}$ demonstrated that there were negligible concentrations of $\left[{ }^{14} \mathrm{C}\right]$ octanol or its more polar metabolites in arterial blood. In contrast to the findings with ethanol, gastric vein blood contained an appreciable concentration of octanol metabolites (see Fig. 4). The ratio of octanol metabolites to octanol in gastric vein blood averaged 1.35 , with a range of 1.04-1.68.

First-pass small bowel metabolism of ethanol. Fig. 5 shows the V-A differences of ethanol and acetate across the intestinal mucosa. The control animals that received only water had no $\mathrm{V}$-A difference in ethanol but had a V-A difference in acetate averaging $0.41 \mathrm{mM}$, apparently due to the production of acetate in the intestinal tract. The animals that received ethanol

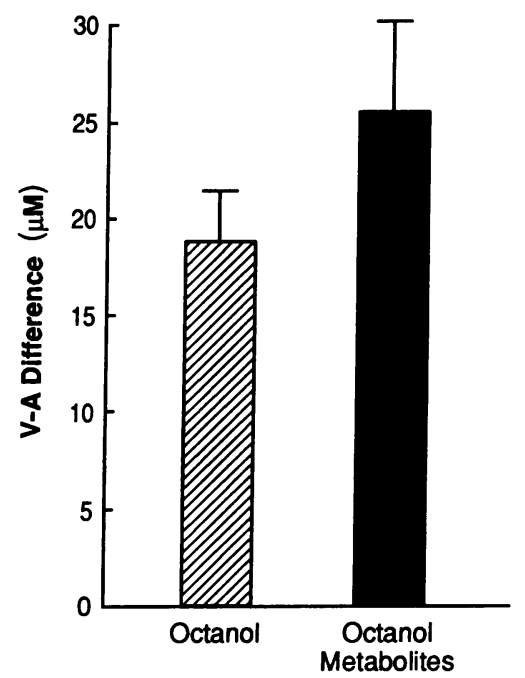

Figure 4. The V-A difference of $\left[{ }^{14} \mathrm{C}\right]$ octanol and $\left[{ }^{14} \mathrm{C}\right]$ octanol metabolites 5 min after intragastric administration of $\left[1-{ }^{14} \mathrm{C}\right]$ octanol. 


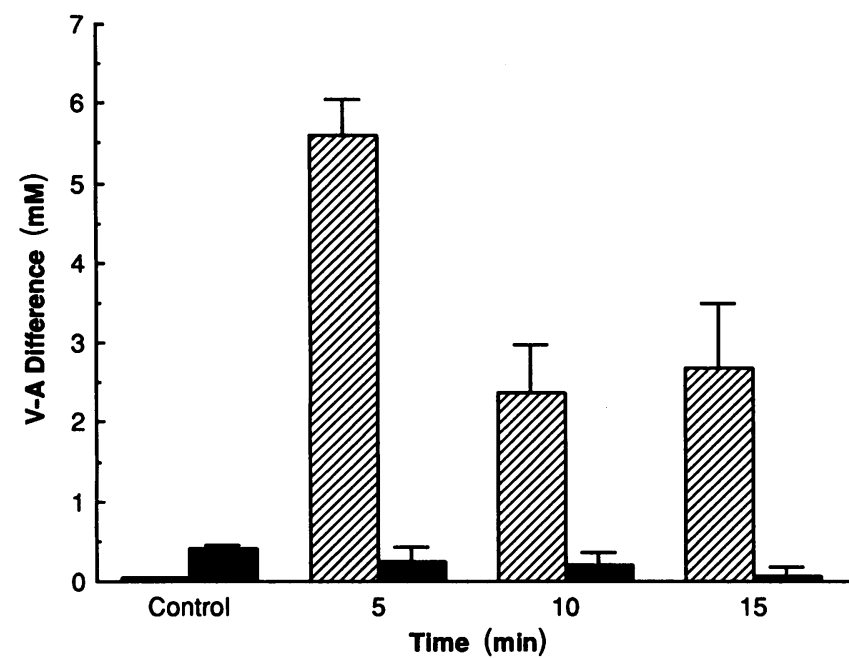

Figure 5. The V-A difference of ethanol and acetate across the jejunum before and at 5,10 , and $15 \mathrm{~min}$ after instillation of ethanol into the jejunum. $\mathrm{E}, \mathrm{ETOH} ; \boldsymbol{m}$, acetate.

had a V-A difference for ethanol of $5.61 \mathrm{mM}$ at $5 \mathrm{~min}, 2.38$ $\mathrm{mM}$ at $10 \mathrm{~min}$, and $2.69 \mathrm{mM}$ at $15 \mathrm{~min}$. The $\mathrm{V}-\mathrm{A}$ difference of acetate at each time period was not significantly different $(P$ $>0.30$ ) from that observed in the control animals. Fig. 6 shows the $\mathrm{V}$-A differences in $\left[{ }^{14} \mathrm{C}\right]$ ethanol and $\left[{ }^{14} \mathrm{C}\right]$ bicarbonate in the animals given $\left[{ }^{14} \mathrm{C}\right]$ ethanol. The $\mathrm{V}-\mathrm{A}$ differences in ethanol averaged $10.1 \mathrm{mM}$ at $5 \mathrm{~min}, 4.04 \mathrm{mM}$ at $10 \mathrm{~min}$, and $1.18 \mathrm{mM}$ at $15 \mathrm{~min}$. The $\mathrm{V}-\mathrm{A}$ differences in $\left[{ }^{14} \mathrm{C}\right]$ bicarbonate were 0.22 , 0.12 , and $0.13 \mathrm{mM}$ at 5,10 , and $15 \mathrm{~min}$, respectively.

Portal vein infusions of ethanol. Fig. 7 demonstrates the influence of the rate of hepatic delivery of identical doses of ethanol on blood ethanol AUCs. Infusion periods of 5, 15, 30, 60 , and 90 min resulted in respective AUCs of 6.8, 5.45, 4.87, 1.89 , and $0.75 \mathrm{mM} / \mathrm{h}$.

\section{Discussion}

Evidence that gastric ADH might play an important role in the metabolism of ingested ethanol has been provided largely by

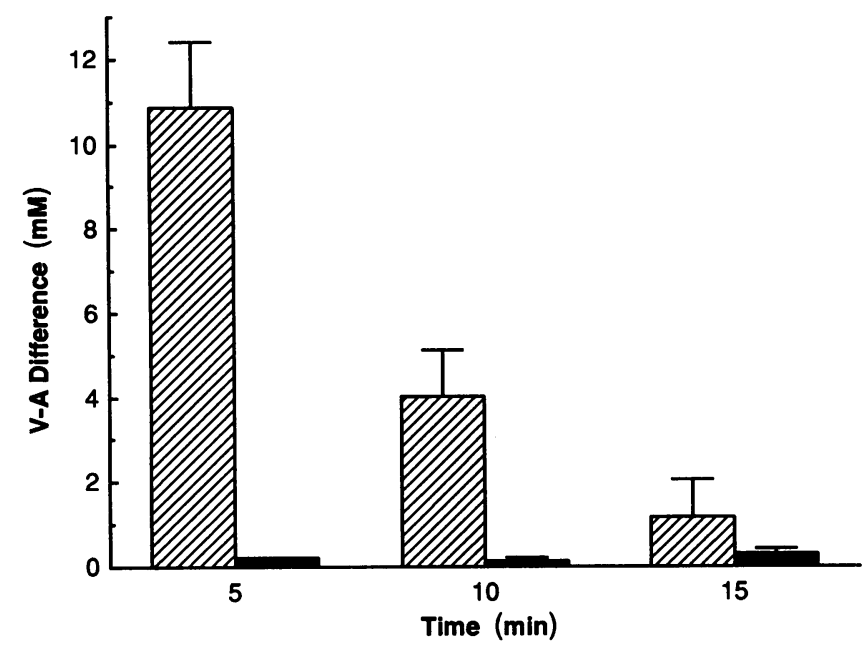

Figure 6. The V-A difference across the jejunum of $\left[{ }^{14} \mathrm{C}\right]$ ethanol and $\left[{ }^{14} \mathrm{C}\right]$ bicarbonate at 5,10 , and $15 \mathrm{~min}$ after instillation of $\left[1-{ }^{14} \mathrm{C}\right]$ ethanol into the jejunum. $\square,\left[{ }^{14} \mathrm{C}\right] \mathrm{ETOH} ; \boldsymbol{\square}\left[{ }^{14} \mathrm{C}\right] \mathrm{HCO}_{3}^{-}$.

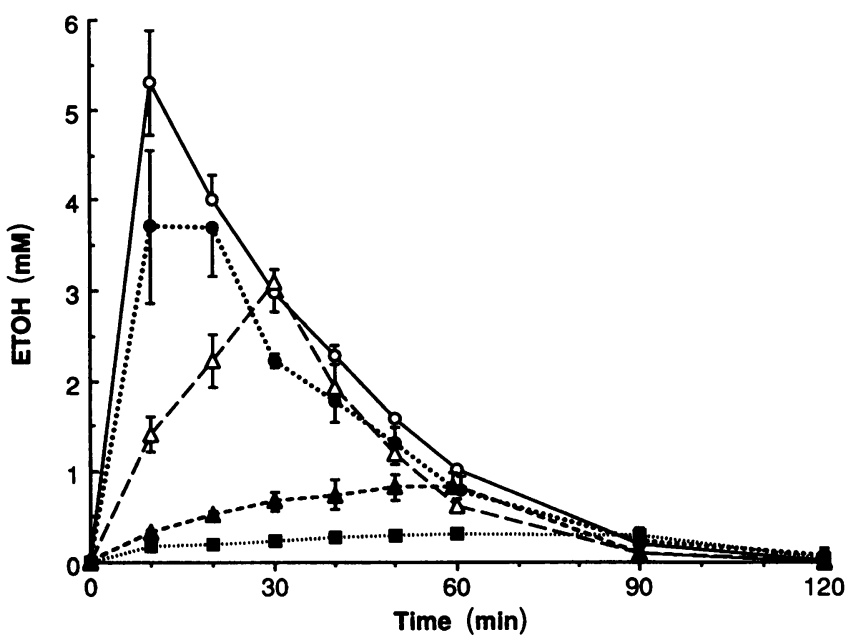

Figure 7. Influence of portal vein infusion rate of ethanol on the AUC. A decreasing rate of administration of a constant dose of ethanol $(0.25 \mathrm{~g} / \mathrm{kg})$ resulted in a decreasing AUC. $\bigcirc-0$, ETOH 5 $\mathrm{min}$, AUC $6.80 \mathrm{mM} / \mathrm{h} ; \bullet \cdots \bullet$, ETOH $15 \mathrm{~min}$, AUC $5.45 \mathrm{mM} / \mathrm{h}$; $\Delta---\Delta$, ETOH $30 \mathrm{~min}$, AUC $4.87 \mathrm{mM} / \mathrm{h} ; \Delta---\Delta$, ETOH $60 \mathrm{~min}$, AUC $1.89 \mathrm{mM} / \mathrm{h} ; \ldots . . \mathrm{ETOH} 90 \mathrm{~min}$, AUC $0.75 \mathrm{mM} / \mathrm{h}$.

comparison of AUCs after oral or intravenous infusion of ethanol in rats $(6,7,12)$ and humans $(8,9,22)$. Although the AUC has been found to be $20-80 \%$ less with oral administration, such reductions have been demonstrable only when small quantities of ethanol were administered with food. For example, Julkunen et al. (6) compared the AUCs obtained with oral and intravenous administration of ethanol to rats in doses of $0.25,0.5$, and $2.5 \mathrm{~g} / \mathrm{kg}$. In fed animals only the two lower doses of ethanol were associated with a statistically reduced AUC, and no influence of route of administration on AUC was demonstrable in fasting animals. A human study comparing oral and intravenous administration of ethanol demonstrated differences in AUC only when the subjects had ingested a meal. In addition, when the dose of ethanol was increased to $0.3 \mathrm{~g} / \mathrm{kg}$, the difference in AUC became insignificant (8).

The percentage of an oral dose of ethanol that undergoes first-pass metabolism in the stomach is determined by the fraction of the dose absorbed from the stomach and the efficiency with which this absorbed ethanol is metabolized by the gastric mucosa. In the present study, we quantitatively assessed these two factors after the oral administration of a small dose of ethanol $(0.25 \mathrm{~g} / \mathrm{kg})$ to fed male rats, the experimental conditions reported to maximize gastric metabolism of ethanol (6).

At $60 \mathrm{~min}, 91 \%$ of the dose had left the stomach, of which $20 \%$ had been absorbed across the gastric mucosa and $71 \%$ had emptied into the duodenum. Thus, roughly $20 \%$ of the original dose was the maximum percentage of ethanol available for gastric metabolism; and virtually $100 \%$ of this ethanol would have to undergo first-pass metabolism if the stomach is to account for just $20 \%$ of the total metabolism.

The percentage of the ethanol metabolized during absorption from the stomach was determined by comparing the gastric V-A difference for ethanol with that of its metabolites (acetaldehyde, acetate, and bicarbonate). The gastric V-A differences for acetaldehyde and acetate across the rat gastric mucosa were $<1 \%$ of the $\mathrm{V}-\mathrm{A}$ difference for ethanol indicating, that $<1 \%$ of the ethanol absorbed from the stomach was metabo- 
lized to these compounds. This finding is similar to that of Lamboeuf et al. $(13,14)$, who used a higher gastric dose of ethanol, $1.15 \mathrm{~g} / \mathrm{kg}$, and measured the portal vein-arterial differences of ethanol, acetaldehyde, and acetate in rats. They found a V-A difference of the metabolites that was only $\sim 1 \%$ of the V-A difference for ethanol.

Carter and Isselbacher (23) reported that gastric and intestinal tissue slices from female Sprague-Dawley rats produced ${ }^{14} \mathrm{CO}_{2}$ when incubated with $\left[{ }^{14} \mathrm{C}\right]$ ethanol. Therefore, we estimated the fraction of ethanol metabolized to $\mathrm{CO}_{2}$ by measuring the gastric $\mathrm{V}-\mathrm{A}$ differences for $\left[{ }^{14} \mathrm{C}\right]$ ethanol and $\left[{ }^{14} \mathrm{C}\right]$ bicarbonate after intragastric instillation of $\left[{ }^{14} \mathrm{C}\right]$ ethanol. Less than $3 \%$ of the ethanol absorbed from the stomach was oxidized to ${ }^{14} \mathrm{CO}_{2}$. Thus, we concluded that $<4 \%$ of the ethanol absorbed from the stomach was metabolized to acetaldehyde, acetate, or $\mathrm{CO}_{2}$. Because only $20 \%$ of the original dose was absorbed across the rat gastric mucosa, gastric metabolism was responsible for $<1 \%$ of the total dose of ethanol. Measurements of V-A differences across the upper small intestine also indicated that there was negligible first-pass metabolism of ethanol in the small bowel.

The inability to demonstrate appreciable gastric metabolism of ethanol in the stomach of the rat was not entirely unexpected, given the content and kinetic characteristics of the ADH present in rat gastric mucosa. Julia et al. $(4,5)$ showed that ethanol is a very poor substrate for the ADH found in rat gastric mucosa, with a reported $K_{\mathrm{m}}$ ranging from 3,000 to 5,000 $\mathrm{mM}$ at $\mathrm{pH}$ 7.5.

On the basis of in vitro measurements of the total ADH activity in the rat stomach (4), if the gastric mucosa were exposed to the roughly $500-\mathrm{mM}$ ethanol concentration instilled into the stomach in our experiments, only $\sim 0.4 \%$ of the dose would be metabolized in $1 \mathrm{~h}$. In reality, the ethanol concentration in the mucosa would be only a small fraction of the luminal concentration because a thick unstirred water layer of $\sim 900 \mu \mathrm{m}$ separates luminal contents from the gastric mucosa of the rat (24). Since the gastric mucosal cell is in close approximation to the capillaries, and since the cell and capillary membranes are very permeable to ethanol, the ethanol concentration in the mucosa should be much closer to that of gastric venous blood (peak of $\sim 20 \mathrm{mM}$ ) than that in the lumen. With a mucosal concentration of $20 \mathrm{mM},<0.04 \%$ of the ethanol dose would be expected to be metabolized by the gastric mucosa in $1 \mathrm{~h}$. Although prediction of in vivo metabolism from in vitro measurements often is far from perfect, gastric mucosal metabolism of ethanol would become appreciable only if the in vitro kinetic parameters underestimated in vivo values for ADH by several orders of magnitude.

In contrast to the situation with ethanol, gastric $\mathrm{ADH}$ has a high affinity for octanol, with a reported $K_{\mathrm{m}}$ of $0.5 \mathrm{mM}$ (5). Using measurements of $\mathrm{V}-\mathrm{A}$ difference, we found that $\sim 66 \%$ of $\left[{ }^{14} \mathrm{C}\right]$ octanol absorbed from the stomach was metabolized during passage across the gastric mucosa. This finding demonstrates that gastric ADH can metabolize low concentrations of a substrate for which it has a high affinity and that this metabolism is readily detected using the $\mathrm{V}$-A difference technique.

Although the finding of lower AUCs with oral than with intravenous ethanol administration repeatedly has been used as evidence of first-pass gastric metabolism of ethanol, this conclusion is valid only when the overall metabolic clearance follows first-order kinetics. If there is saturation of the clearance mechanism, as is the case with ethanol (14), the rate of delivery of ethanol to the liver in portal blood becomes an important determinant of AUC. For example, if the absorption rate of a dose of ethanol is sufficiently slow to maintain the portal ethanol concentration below the $V_{\max }$ of hepatic $\mathrm{ADH}$, little ethanol will escape into the peripheral circulation and there will be a very low AUC. In contrast, if the same dose of ethanol is more rapidly absorbed, such that the delivery rate to the liver exceeds the hepatic $V_{\max }$, a much greater AUC will be observed. The dramatic influence of the rate of hepatic delivery of ethanol on the AUC is illustrated in Fig. 7. In this study, the same quantity of ethanol $(0.25 \mathrm{~g} / \mathrm{kg})$ was infused into the portal vein over increasingly longer periods of time. With a 5-min infusion the AUC was $6.8 \mathrm{mM} / \mathrm{h}$, and this value declined with increasing length of infusion, reaching an AUC of only $0.74 \mathrm{mM} / \mathrm{h}$ with a 90-min infusion. Thus, before differences in AUCs between groups of subjects can be attributed to first-pass gastric metabolism of ethanol, it must be demonstrated that ethanol was delivered to the liver at the same rate in the two groups. A similar demonstration is required when different AUCs are to be used as evidence that some manipulation influences gastric ethanol metabolism in a given individual. Factors that could alter the delivery rate of ethanol, such as differences in gastric emptying or gastric absorption of ethanol, never have been excluded in published studies.

Meaningful comparison of AUCs obtained with oral versus intravenous administration of ethanol requires a similar rate of ethanol delivery to the liver. In most reports ethanol delivery was far more rapid with the intravenous infusion; therefore, a greater AUC would be expected with intravenous than with oral administration and gastric metabolism need not be implicated. The finding that oral and intravenous administration of ethanol yields similar AUCs in fasted animals or animals receiving high doses of ethanol has been attributed to reduced gastric metabolism resulting, respectively, from rapid gastric emptying or saturation of gastric ADH. An alternative explanation is that rapid gastric emptying and high doses of ethanol both yield a rapid hepatic delivery of ethanol that exceeds the $V_{\max }$ of clearance. As a result, the quantity of ethanol reaching the systemic circulation with the oral dosing is comparable to that of the intravenous infusion.

We conclude that there is negligible first-pass metabolism of ethanol in the rat stomach. Although the possibility cannot be excluded that such metabolism occurs in the human stomach, the impetus to look for first-pass gastric metabolism in humans was observations made in the rat. The percentage of ethanol metabolism purported to occur via first-pass gastric metabolism in humans is roughly of the same order as in the rat, and the same AUC technique used in rats is the major evidence for first-pass metabolism in humans. Last, although human gastric mucosal $\mathrm{ADH}$ has a lower $K_{\mathrm{m}}$ for ethanol than does the rat enzyme, in vitro measurements of human gastric $\mathrm{ADH}$ activity are relatively unimpressive. For example, a recent paper reported that the rate of ethanol oxidation by human gastric mucosal $\mathrm{ADH}$ at $\mathrm{pH} 7.5$ and an ethanol concentration of $50 \mathrm{mM}$ was $\sim 2 \mathrm{nmol} \mathrm{NADH} / \mathrm{min}$ per $\mathrm{mg}$ of cytosolic protein (25). Assuming a total gastric mucosal cytosolic protein of roughly $20 \mathrm{~g}$ (10\% of $200 \mathrm{~g}$ of mucosa), this ADH activity would oxidize only $\sim 2 \mathrm{mmol}$ or $\sim 0.4 \%$ of the administered dose of ethanol in $1 \mathrm{~h}$.

On the basis of our finding of negligible gastric ethanol metabolism in the rat and the lack of evidence for this phenomenon in humans, we believe that the concept of appreciable 
first-pass gastric metabolism of ethanol should be considered speculative until direct supporting evidence is presented.

\section{Acknowledgments}

This work was supported in part by Veterans Affairs Funds and National Institute of Diabetes and Digestive and Kidney Diseases grant 2-RO1-DK-133309-22.

\section{References}

1. Pestalozzi, D. M., R. Buhler, J. P. von Wartburg, and M. Hess. 1983. Immunohistochemical localization of alcohol dehydrogenase in the human gastrointestinal tract. Gastroenterology. 85:1011-1016.

2. Hempel, J. D., and R. Pietruszko. 1979. Human stomach alcohol dehydrogenase: isoenzyme composition and catalytic properties. Alcohol. Clin. Exp. Res. 3:95-98.

3. Cederbaum, A. I., R. Pietruzko, J. Hempel, F. F. Becker, and E. Rubin. 1975. Characterization of a nonhepatic alcohol dehydrogenase from rat hepatocellular carcinoma and stomach. Arch. Biochem. Biophys. 171:348-360.

4. Julia, P., M. D. Boleda, and X. Pares. 1987. Kinetic properties and physiological significance of the ADH-1' isoenzyme of rat stomach alcohol dehydrogenase. In Enzymology and Molecular Biology of Carbonyl Metabolism. A. Weiner and T. G. Flynn, editors. Alan R. Liss, Inc., New York. 189-201.

5. Julia, P., J. Farres, and X. Pares. 1987. Characterization of three isoenzymes of rat alcohol dehydrogenase: tissue distribution and physical and enzymatic properties. Eur. J. Biochem. 162:179-189.

6. Julkunen, R. J. K., L. Tannenbaum, E. Baraona, and C. S. Lieber. 1985. First pass metabolism of ethanol: an important determinant of blood levels after alcohol consumption. Alcohol. 2:437-441.

7. Caballeria, J., E. Baraona, and C. S. Lieber. 1987. The contribution of the stomach to ethanol oxidation in the rat. Life Sci. 41:1021-1027.

8. DiPadova, C., T. M. Worner, R. J. K. Julkunen, and C. S. Lieber. 1987. Effects of fasting and chronic alcohol consumption on the first-pass metabolism of ethanol. Gastroenterology. 92:1169-1173.

9. Frezza, M., C. DiPadova, G. Pozzato, M. Terpin, E. Baraona, and C. S. Lieber. 1990. High blood alcohol levels in women: the role of decreased gastric alcohol dehydrogenase activity and first-pass metabolism. N. Engl. J. Med. 322:95-99.

10. Caballeria, J., E. Baraona, M. Rodamilans, and C. S. Lieber. 1989. Effects of cimetidine on gastric alcohol dehydrogenase activity and blood ethanol levels. Gastroenterology. 96:388-392.

11. Roine, R., R. Gentry, R. Hernandez-Munoz, E. Baraona, and C. Lieber.
1990. Aspirin increases blood alcohol concentrations in humans after ingestion of ethanol. JAMA (J. Am. Med. Assoc.). 264:2406-2408.

12. Julkunen, R. J. K., C. DiPadova, and C. S. Lieber. 1985. First pass metabolism of ethanol-A gastrointestinal barrier against the systemic toxicity of ethanol. Life Sci. 37:567-573.

13. Lamboeuf, Y., P. H. LaDroitte, and G. de Saint-Blanquat. 1983. The gastro-intestinal metabolism of ethanol in the rat: effect of chronic alcoholic intoxication. Arch. Int. Pharmacodyn. 261:157-169.

14. Lamboeuf, Y., G. De Saint-Blanquat, and R. Derache. 1981. Mucosal alcohol dehydrogenase- and aldehyde dehydrogenase-mediated ethanol oxidation in the digestive tract of the rat. Biochem. Pharmacol. 30:542-545.

15. Benet, L. Z., J. R. Mitchell, and L. B. Sheiner. 1990. Pharmacokinetics: the dynamics of drug absorption, distribution, and elimination. In The Pharmacological Basis of Therapeutics. A. G. Goodman, T. W. Rall, A. S. Nies, and P. Taylor, editors. Pergamon Press, New York.

16. Rall, T. W. 1990. Hypnotics and sedatives: ethanol. In The Pharmacological Basis of Therapeutics. A. G. Goodman, T. W. Rall, A. S. Nies, and P. Taylor, editors. Pergamon Press, New York. 345-382.

17. Cooke, A. R., and A. Birchall. 1969. Absorption of ethanol from the stomach. Gastroenterology. 57:269-272.

18. Suokas, A., O. Forsander, and K. Lindros. 1984. Distribution and utilization of alcohol-derived acetate in the rat. J. Stud. Alcohol. 45:381-385.

19. Giles, H. G., S. Meggiorini, and E. I. Vidins. 1986. Semiautomated analysis of ethanol and acetate in human plasma by head space gas chromatography. Can. J. Physiol. Pharmacol. 64:717-719.

20. Coldwell, B. B., G. Solomonraj, H. L. Trenholm, and G. S. Wiberg. 1971. The gas chromatographic estimation of ethanol, acetaldehyde and acetone in ethanol metabolism studies. Clin. Toxicol. 4:99-113.

21. DeMaster, E. G., F. N. Shirota, and H. T. Nagasawa. 1986. Role of propiolaldehyde and other metabolites in the pargyline inhibition of rat liver aldehyde dehydrogenase. Biochem. Pharmacol. 35:1481-1489.

22. Caballeria, J., M. Frezza, R. Hernandez-Munoz, C. DiPadova, M. A Korsten, E. Baraona, and C. S. Lieber. 1989. Gastric origin of the first-pass metabolism of ethanol in humans: effect of gastrectomy. Gastroenterology. 97:12051209.

23. Carter, E. A., and K. J. Isselbacher. 1971. The metabolism of ethanol to carbon dioxide by stomach and small intestinal slices. Proc. Soc. Exp. Biol. Med. 138:817-819.

24. Duane, W. C., M. D. Levitt, N. A. Staley, A. P. McHale, D. M. Wiegand, and C. A. Fetzer. 1986. Role of the unstirred layer in protectin the gastric mucosa from bile salt. Gastroenterology. 91:913-918.

25. Hernandez-Munoz, R., J. Caballeria, E. Baraona, R. Uppal, R. Greenstein, and C. S. Lieber. 1990. Human gastric alcohol dehydrogenase: its inhibition by $\mathrm{H}_{2}$-receptor antagonists, and its effect on the bioavailability of ethanol. Alcohol. Clin. Exp. Res. 14:946-950. 